\title{
Advanced heterogeneous diesel combustion with ultra-low engine emissions and low fuel consumption levels
}

\author{
Uwe Wagner and Ulrich Spicher
}

\begin{abstract}
Increasingly stringent emissions regulations, limited reserves of fossil fuels and $\mathrm{CO}_{2}$-related climate effects have led to the demand for new and diversified engine and vehicle technologies. Compression ignition combustion processes currently offer the highest thermal efficiencies and therefore low specific fuel consumption. Nevertheless, conventional diesel engines face challenges in decreasing $\mathrm{NO}_{x}$ and particulate emissions if they are to meet ever more stringent emission regulations. An overview of advanced Diesel technologies and possible ways to address these challenges will be presented in this paper. A recently developed combustion process will be highlighted in detail to demonstrate the emission reduction potential of heterogeneous diesel combustion while maintaining a high thermal efficiency. This combustion process is based on the spatial separation of the different part injections performed during one cycle and offers major advantages in terms of oxygen use, increased exhaust gas recirculation tolerance and significantly lower levels of pollutant formation. This injection strategy is realized by integrating a second injector into the cylinder head of a single cylinder research engine. This second injector is used for the pilot injection and the centrally placed standard injector is used for the main injection. This configuration allows the pilot and main fuels to be injected into different areas of the cylinder. Additionally, the flexible configuration of the proposed injection system allows easy implementation of alternative combustion processes such as homogeneous or partially premixed combustion.
\end{abstract}

\section{Keywords}

Diesel engine, compression ignition, injection strategy, pilot injection, alternative combustion process

\section{Introduction}

Diesel engines with direct fuel injection are currently the most efficient propulsion systems for vehicle applications. Ever more stringent emission regulations, especially for particulate and $\mathrm{NO}_{x}$ emissions, formulated in response to environmental and health concerns are creating significant challenges for engine manufacturers. Conventional diesel engines offer a high thermal efficiency and therefore will play a key role in reducing fuel consumption and $\mathrm{CO}_{2}$-induced global warming. However, these engines have the major drawbacks of relatively high soot and $\mathrm{NO}_{x}$ emissions that are the result of the direct fuel injection and resulting combustion process. The combustion in conventional diesel engines leads to rich regions in the local air/fuel ratio $\lambda$ where $\lambda \ll 1$ and to local air/fuel ratios of $\lambda=1$. This heterogeneous mixture simultaneously causes soot because of the rich areas and $\mathrm{NO}_{x}$ due to the creation of high burning temperature zones (Zeldovich mechanism). Utilizing conventional methods both emission components cannot be reduced at the same time which is called the soot- $\mathrm{NO}_{x}$ trade-off. ${ }^{1,2}$

Against this background, with additional momentum from the limited reserves of fossil fuels, attention needs to be focused on the development and use of advanced engine technologies with very low fuel consumption and even further reduced pollutant emissions.

Different technical approaches that could possibly be used to meet the regulatory emission requirements while maintaing high thermal efficiencies can be seen in

Institut für Kolbenmaschinen, Karlsruhe Institute of Technology, Germany

Corresponding author:

Uwe Wagner, Institut für Kolbenmaschinen, Karlsruhe Institute of Technology (KIT), Rintheimer Querallee 2, Karlsruhe 76I3I, Germany. Email: Uwe.Wagner@kit.edu 


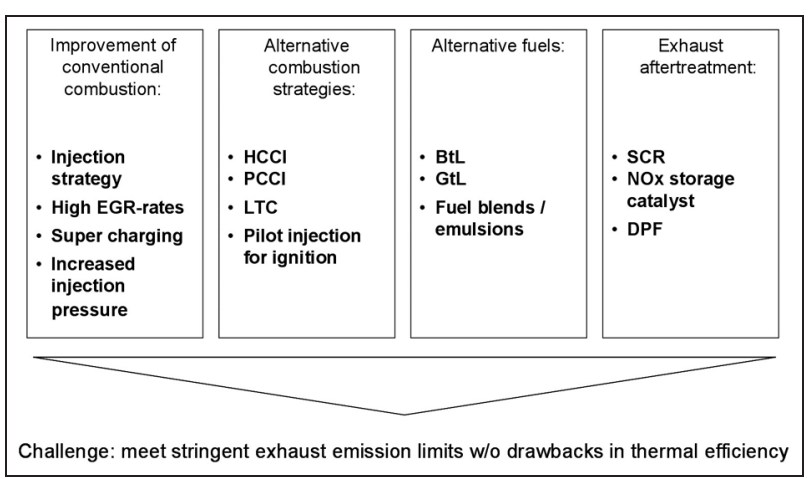

Figure I. Technical approaches to reduce pollutant emissions.

Figure 1. These approaches can be divided into the following basic strategies:

(a) improvement of conventional combustion systems;

(b) the realization of alternative combustion systems;

(c) the use of alternative fuels;

(d) the application of sophisticated after-treatment systems for the exhaust gas;

(e) combinations of these technologies.

A major area of diesel combustion development concerns the improvement of conventional combustion systems, which basically means the combustion of more or less heterogeneous mixtures and ignition control by injection timing. One significant approach is to continuously increase the injection pressure to improve the atomization process for better combustion and emission characteristics. ${ }^{3}$ This pressure increase goes in parallel with very precise injection timing and quantity control as well as sophisticated rate shaping capabilities to address issues such as low emission and low noise combustion, stable combustion, high exhaust gas recirculation (EGR) tolerance, robustness and lifetime accuracy, refer, for example, to Atzler et al. ${ }^{4}$ and Hermann et al. ${ }^{5}$ Improved boosting capabilities are necessary to overcome the problem of excessive soot formation at high EGR rates since they keep the available amount of oxygen to a sufficient level. Therefore, improved variable turbine geometries and two-stage turbo charging processes are technologies which are being increasingly applied in modern engines. Apart from multiple injections and injection rate shaping to create temporal separation of the different part injections a promising alternative for conventional combustion processes is the spatial separation of the different part injections. This strategy will be addressed in more detail later in this paper.

Alternative combustion processes represent a further way to simultaneously reduce both soot and $\mathrm{NO}_{x}$ emissions while still offering high thermal efficiencies. In general, most of the different approaches basically create partly or completely homogenized mixtures of air, fuel and recirculated exhaust gas to achieve combustion with a low peak temperature due to mixture dilution.
This avoids thermal $\mathrm{NO}_{x}$ formation and due to the homogeneous mixtures soot formation (for example, homogenous charge compression ignition (HCCI), premixed charge compression ignition (PCCI), low temperature combustion (LTC)). ${ }^{6}$ In the area of gas engines the ignition of very lean air/fuel mixtures is realized using a small amount of diesel fuel to start combustion. A possible way to adopt a combination of PCCI and pilot injection for ignition of liquid fuels is demonstrated by Curran et al. ${ }^{7}$ This appears to be a promising approach to use gasoline and diesel fuel to achieve very low emissions and high thermal efficiency levels.

A third possibility, mainly of course in combination with other described technologies, is to use alternative fuels that have different properties compared with fossil-based liquid fuels to reduce pollutant emission formation during combustion. In addition to the improved mixture preparation and ignition delay characteristics offered by 'designed' fuels such as gasto-liquid (GtL) or biomass-to-liquid (BtL) attention is also being paid to oxygenated fuels. Although these designed fuels have a slightly decreased calorific value, they offer significant advantages in reducing soot formation during combustion and increased EGR tolerance, respectively. One approach to facilitate this effect is to use blended fuels to influence the engine-out soot levels and $\mathrm{NO}_{x}$ emissions of combustion engines. The use of different fuel compositions in the form of diesel-ethanol emulsions and dieselethanol-water emulsions offers a significant potential to reduce emissions. Experimental investigations, for example, those performed at the Institut für Kolbenmaschinen have shown that by adding ethanol to diesel fuel, engine-out soot emission levels can be lowered considerably. The addition of water lowers the $\mathrm{NO}_{x}$ emission level. For details please refer to Bach et al. ${ }^{8}$

Exhaust gas after-treatment is of course another practical solution to meet stringent emission regulations. In recent years many technical solutions have been developed that can significantly reduce $\mathrm{NO}_{x}$ and particulate emission levels. A challenge for particulate filter systems is the regeneration process of the filter. In light-duty applications this is mainly realized by increasing the exhaust gas temperature by retarding the combustion timing and injecting additional fuel either into the cylinder or into the exhaust duct. This leads to increased fuel consumption during regeneration and can also cause oil dilution problems. Medium and heavy-duty applications often use filters where regeneration is mainly based on continuous oxidation of soot with $\mathrm{NO}_{2}$. For sufficient regeneration a certain level of the $\mathrm{NO}_{2}$-to-soot ratio is required, which again can cause problems with increased $\mathrm{NO}_{2}$ emissions. Therefore, in more recent applications $\mathrm{NO}_{x}$ aftertreatment systems such as lean $\mathrm{NO}_{x}$ storage catalysts $\left(\mathrm{NO}_{x}\right.$ traps) or selective catalytic reduction (SCR) systems are used. Again these systems cause fuel penalties, 
for example, the rich operation required to regenerate the $\mathrm{NO}_{x}$ trap or alternatively an additional operating fluid like urea-based AdBlue ${ }^{\mathrm{TM}}$ has to be used. The main objective for engine and exhaust after-treatment system development has to be to find the best solution in terms of durability, cost and overall fuel economy. ${ }^{9}$

\section{Advanced conventional combustion strategy}

In the following, the concepts and realization of a spatially separated pilot and main fuel injection strategy will be described. Additionally, experimental results which were obtained using a single cylinder research engine will be analysed and discussed.

\section{Fundamentals}

A significant contributor to soot formation during combustion is the interaction between the very rich air/fuel mixture, and in some cases liquid fuel, with the flame. This effect appears to frequently occur in modern direct injection diesel engines where the injection is often split into pilot and main injections in order to minimize noise levels. After the ignition of the pre-injected fuel a part of the main injection can interact with the flame while it is still in its liquid phase or as a rich air/fuel mixture since the fuel is injected straight towards the already burning cylinder areas. This leads to the formation of high amounts of soot. ${ }^{10}$

As previously mentioned, different injections such as the pilot injection, main injection and possibly a post injection can occur in one cycle. Usually, these individual injections are performed with the same injection hardware and injector and therefore the fuel is injected into the same cylinder areas. Hence, a strong interaction between the individual injections is evident under the prevailing combustion conditions.

Significant reductions in combustion noise and $\mathrm{NO}_{x}$ emissions compared with an engine operation without pilot injection can be achieved by injecting a small amount of fuel before the main injection. The pre-injected fuel starts to burn and increases the temperature in the combustion chamber before the main injection occurs. This increased temperature reduces the ignition delay for the main fuel and the ratio of premixed to diffusion-controlled combustion is decreased. Consequently, the maximum pressure gradient and peak temperature during the combustion decreases which lowers both the engine noise and the formation of $\mathrm{NO}_{x}$.

Unfortunately, the large fraction of diffusioncontrolled combustion leads to higher soot emissions. This becomes even more apparent with an increasing amount of pre-injected fuel where the soot emissions rise disproportionately. However, diffusion-controlled combustion is not solely responsible for high soot

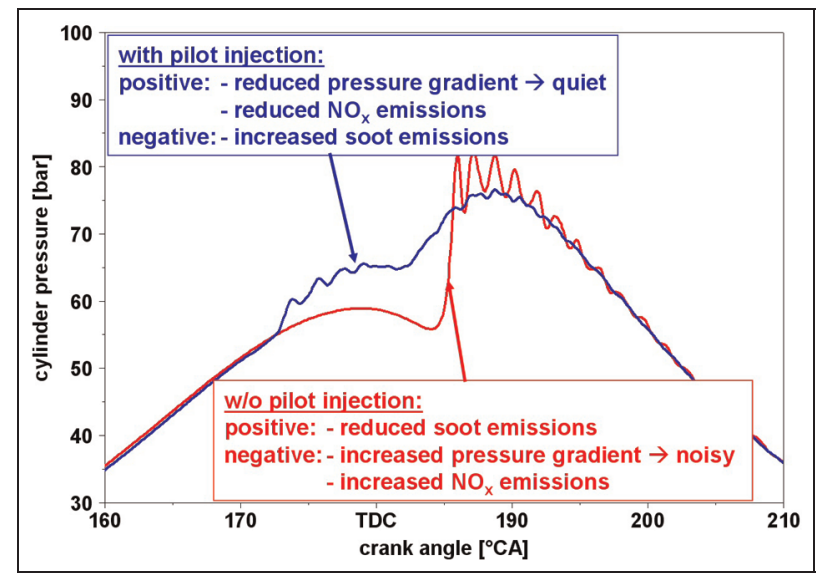

Figure 2. Cylinder pressure with and without (w/o) pilot injection.

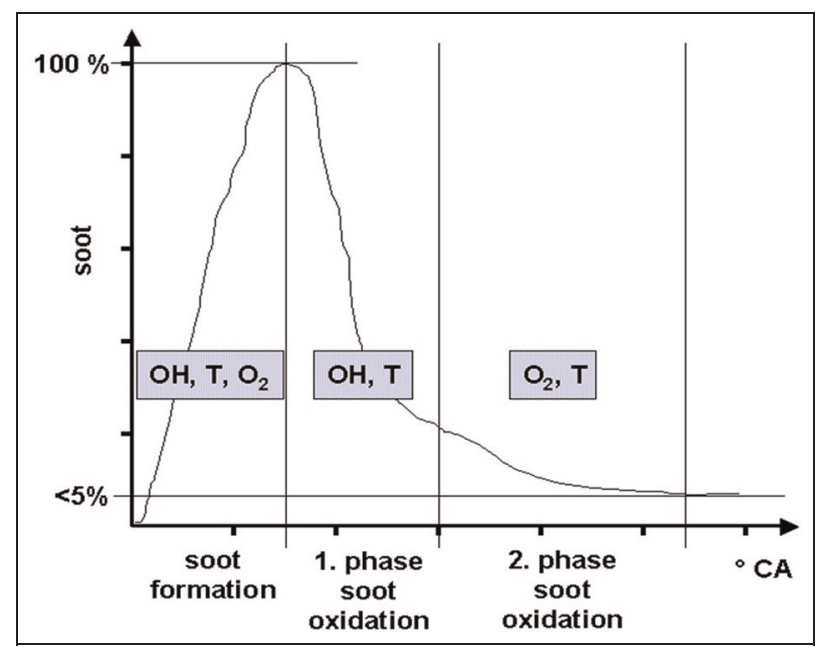

Figure 3. Qualitative characteristic process of the soot formation and oxidation. ${ }^{13,14}$

emissions; several other factors contribute. The local air/fuel ratio $\lambda$ for the main injected fuel is reduced due to the already burned pilot fuel, which both increases the soot formation and decreases soot oxidation during the combustion. Additionally, a direct contact of injected and liquid fuel with the potentially still burning pilot fuel can take place which can lead to very high levels of soot formation. Figure 2 shows an example of the cylinder pressure with and without pilot injection. The advantage of the pilot injection strategy in reducing the maximum pressure gradient due to a smaller part of premixed combustion during the combustion can be seen clearly. Nevertheless, a major disadvantage is the significantly increased soot emission. ${ }^{11,12}$

The characteristic progression of the soot concentration in the cylinder during the combustion process is shown in Figure 3. ${ }^{13,14}$ This qualitative soot formation and oxidation process is found both in simulation models and different diesel and direct injection gasoline 


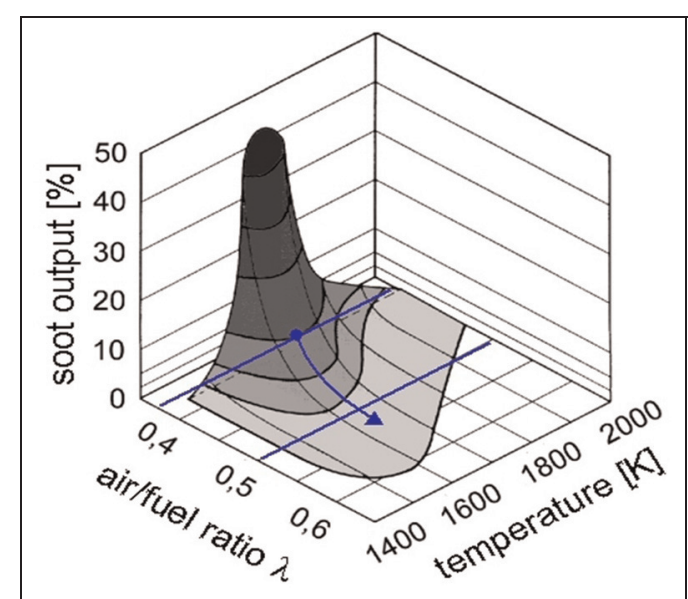

Figure 4. Temperature and $\lambda$ conditions for soot formation. ${ }^{17,18}$

engines. ${ }^{15}$ The whole process is divided into an initial soot formation phase, which usually initiates at less than $2^{\circ}$ crank angle (CA) after the start of combustion with a duration of $10-20^{\circ} \mathrm{CA}$, in which the in-cylinder soot concentration rises and two subsequent soot oxidation phases in which the in-cylinder soot concentration decreases. The key factors that influence these processes will now be discussed. It can be seen that for both the soot formation part and the second oxidation phase the oxygen concentration is a key parameter that influences the final soot emission level. ${ }^{16}$ The effect of the local air/fuel ratio $\lambda$ and the temperature on the amount of emitted soot is shown in Figure $4 .^{17}$ These results were obtained in premixed flame experiments and at pressure and temperature conditions that are representative of diesel engines. A small increase in the local air/fuel ratio $\lambda$ results in a significant decrease in the soot emission level. In fact Böhm et al. ${ }^{18}$ subsequently showed that soot formation could be completely suppressed when the local air/fuel ratio was always kept above $\lambda=0.6$ 0.7 during the combustion. Hopp ${ }^{16}$ demonstrated using both calculations and experiments that the locally available oxygen content during the combustion is a key parameter especially for the soot oxidation process and hence for the soot emission level.

Starting from these boundary conditions that influence the soot formation, a combustion process was designed in a way to increase the locally available amount of oxygen during the combustion to lower the engine-out soot emission level.

\section{Combustion process and test engine}

Basic idea. A new injection strategy was derived that addresses the discussed issues related to direct injection heterogeneous combustion. The proposed strategy is characterized by a spatial separation of the different part injections in one cycle. The spatial separation of the particular part injections allows the negative interaction between pilot and main injection, in terms of fuel and flame contact, to be avoided and, even more important, increases the local air fuel/ratio $\lambda$ for the main injection and therefore reduces the soot emissions.

The pilot fuel injection is directed towards the central area of the combustion chamber and then the main fuel is injected using a conventional spray pattern with a cone angle greater than $160^{\circ}$. With this spatial separation the fuel, injected during the pilot injection phase, burns in a different area in the cylinder than the main fuel and hence does not reduce the local air/fuel ratio $\lambda$ for the main combustion as would be the case with a conventional pilot and main injection strategy using the same injector and spray holes.

Figure 5 shows a simple schematic drawing of how to realize spatial separation for two pilot injection sprays and seven main injection sprays. To separate the two part injections two different injectors are used and this allows the maximum possible spatial distance between the pilot and main injection to be achieved.

Of course, Figure 5 is only a schematic diagram since it shows the pilot and main fuel sprays simultaneously. For real engine operation the pilot injection is done before the main injection with injection timings comparable to conventional pilot injection strategies. This figure also shows the first investigated configuration with two pilot fuel sprays. The results obtained with this configuration together with additional computational fluid dynamics (CFD) simulations led to a new configuration with four pilot fuel sprays, which will be discussed in the following section.

Technical realization and test engine. The test engine is a single cylinder heavy duty engine with direct injection. The cylinder head is an OM 457 from Daimler AG, which offers enough space for the integration of a second injector for the spatially separated pilot injection, for an optical access and for the cylinder pressure indication sensor without any influence on the combustion process. Pertinent data for this engine can be seen in Table 1.

The direct injection is provided by a modern common rail system capable of injection pressures up to 2500 bar. Diesel pressures in this range are necessary when investigating a modern diesel combustion process. The pilot and main injections are controlled by a

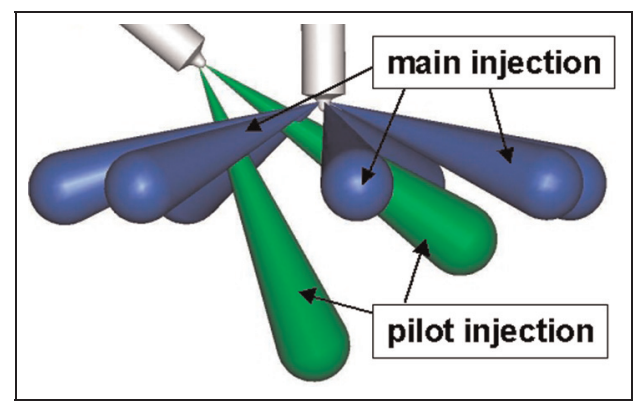

Figure 5. A schematic drawing of the proposed injection strategy. 
Table I. Engine data.

\begin{tabular}{ll}
\hline Property & Value \\
\hline Displacement & $1827 \mathrm{~cm}^{3}$ \\
Stroke & $142 \mathrm{~mm}$ \\
Bore & $128 \mathrm{~mm}$ \\
Compression ratio & $16.1: \mathrm{I}$ \\
EGR & External cooled high pressure \\
Boost pressure & $2.2 \mathrm{bar}$ abs. (max.) \\
Engine speed & $2000 \mathrm{r} / \mathrm{min}(\max )$. \\
Injection pressure & $2500 \mathrm{bar}$ (max.) \\
Coolant/oil temperature & $80^{\circ} \mathrm{C}$ \\
\hline
\end{tabular}

Genotec control system. This provides independent, fully flexible control of each fuel injector.

The cylinder head does not have a bleeder throttle between the outlet valves, so it is possible to place a second injector for the pilot injection in the case of spatially separated pilot injection. The modifications to the cylinder head can be seen in Figure 6. The pilot injector is built into the head via a sleeve with a $40^{\circ}$ angle to the bottom plane, so it is possible to realize a spatially separated pilot injection towards the middle of the piston bowl. In order to precisely position and fix the second injector, additional material has been mounted on the head. The cylinder pressure is measured using an extra compact cylinder pressure transducer from AVL, which is fitted to the cylinder head.

As previously mentioned, the main feature of the proposed system is the spatial separation of the main and pilot injection for a better utilization of the oxygen in the combustion chamber. The proposed experimental setup features a pilot injection with four spray jets that are directed into the inner piston bowl (see Figure 7).

\section{Optical setup for two-colour method}

The two-colour method is a pyrometric measurement technique based on the theory of Planck's radiation law. The measured radiation from soot particles in a luminous flame allows the calculation of the soot and/ or flame temperature and the soot concentration. For details please refer to Mayer. ${ }^{15}$

Luminous flames emit thermal radiation caused by the incandescent soot particles that are typically created in the diffusion-controlled flames that occur in diesel engines and engines with direct gasoline injection running in the stratified mode. Figure 8 shows the experimental setup used for the two-colour method studies. An optical probe, that observes a cone-shaped volume with a cone angle of $27^{\circ}$, is mounted on the cylinder head. The results obtained using this technique shown in this paper were obtained using the optical access shown in Figure 6; thus the radiation of the main injection which makes the major contribution to the soot formation can be seen. The detected radiation is led to the photodiode module by means of an optical fibre bundle that bifurcates into three arms. The photodiode module measures the radiation at three wavelengths: 600,750 and $900 \mathrm{~nm}$. Therefore, band-pass filters with a band width of about $\lambda_{\text {FWHM }}=3 \mathrm{~nm}$ are used. A tungsten band lamp calibrated on a black body temperature of $T \mathrm{~s}=2395 \mathrm{~K}$ at a wavelength of $650 \mathrm{~nm}$ was used to calibrate the system. The temperature and soot concentration were evaluated from 50 cycles of light signals. The sampling rate was $0.1^{\circ} \mathrm{CA}$.

With the new cylinder head it is possible to use the two-colour method for the pilot and the main injection spray separately. Thus, it is possible to measure the difference in soot radiation from different injection strategies both for the pilot fuel sprays and the main fuel sprays at different locations in the combustion chamber. This allows a precise differentiation of the contribution of the part injections to soot formation.

\section{Experimental results}

To compare the injection strategy with a spatial separation of the pilot injection with a conventional injection

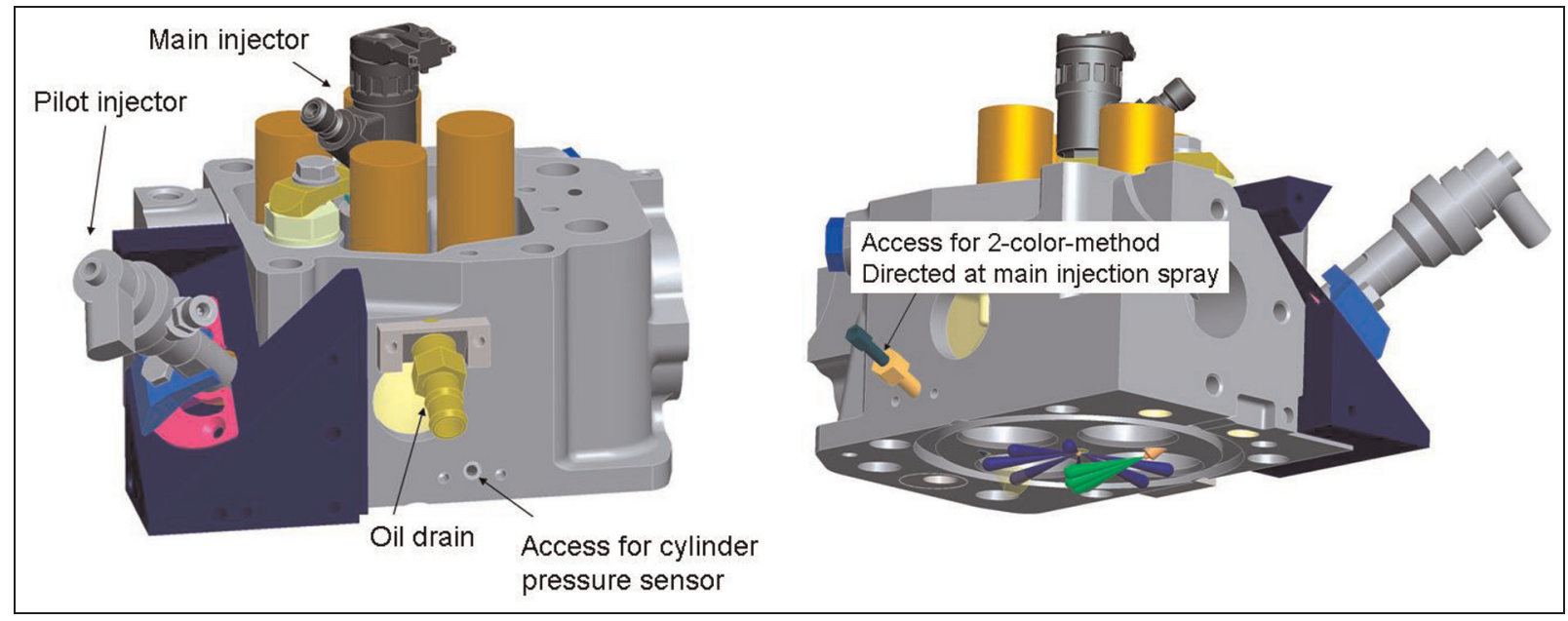

Figure 6. Cylinder head with pilot injector. 


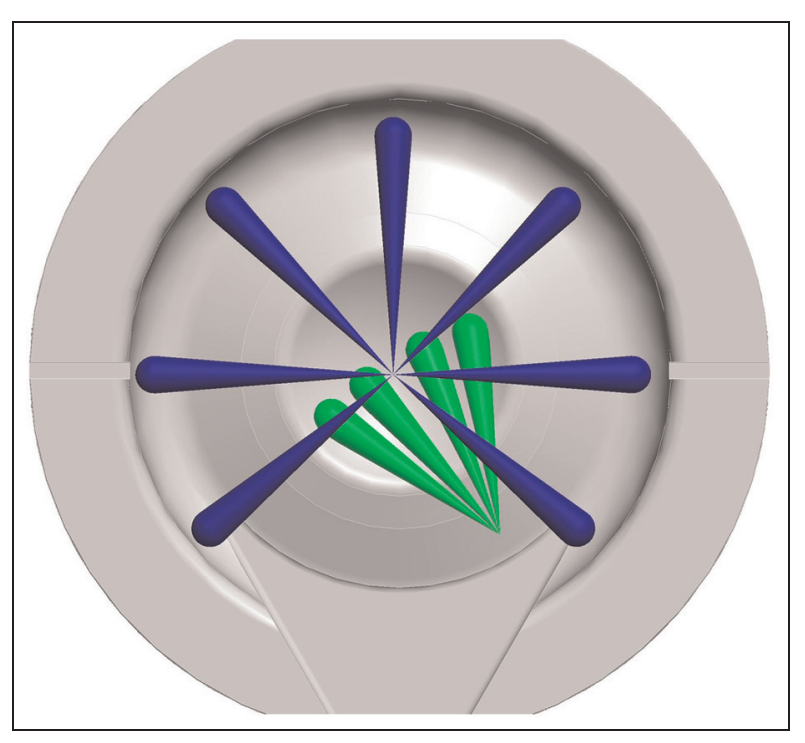

Figure 7. Main (blue spray cones) and pilot (green spray cones) injections into the piston (top view).

strategy and to get information about the potential with respect to soot reduction and $\mathrm{NO}_{x}$ emission behaviour, investigations with different injection timings were performed. For a direct comparison of the emissions of the proposed injection strategy and a conventional strategy, the pilot injection in the conventional case was performed using the standard injector. After that the pilot injection was switched to the second injector; however, the main fuel was still injected with the centrally placed standard injector. In a second step, the pilot fuel quantity was varied to assess the sensitivity of the combustion, and here especially of the soot emissions, on the amount of pilot fuel since in conventional pilot injection this is a critical aspect for application.

For the experimental investigations presented here, the engine speed was set to $1175 \mathrm{r} / \mathrm{min}$ which is based on the medium engine speed used in the World harmonized steady state cycle (WHSC) and to 6 bar indicated mean effective pressure which is a characteristic part load in the WHSC. The engine was operated without EGR, however, one-dimensional CFD calculations suggested that only a small residual gas fraction of about $7 \%$ actually had any effect on the combustion.

\section{Combustion and emission behaviour}

Table 2 shows the operating parameters used in the experiments. Basically the injection timing for the pilot and main injection were varied from $12^{\circ} \mathrm{CA}$ before (BTDC) to $6^{\circ} \mathrm{CA}$ after top dead centre (ATDC) in steps of $3^{\circ} \mathrm{CA}$ while the dwell time between pilot and main injection was constant with $12^{\circ} \mathrm{CA}$.

As previously mentioned, the two critical pollutant emissions from diesel engines are the $\mathrm{NO}_{x}$ and soot emissions. Usually, they show a significant trade-off independence on the different parameters that can be used to influence these emissions. One important parameter to control the combustion timing, and with that premixed and diffusion-controlled amount of combustion, combustion noise and emission formation, is the injection timing which can in turn be controlled by the start of injection (SOI) or start of energizing (SOE) of the injector, respectively. Figure 9 shows the soot- $\mathrm{NO}_{x}$ trade-off for an injection timing variation from $12^{\circ} \mathrm{CA}$ BTDC to $6^{\circ} \mathrm{CA}$ ATDC in steps of $3^{\circ} \mathrm{CA}$. The black line represents the $\mathrm{NO}_{x}$ and soot emission for a conventional pilot injection strategy (pilot and main injection performed with the same injector) and the green line represents the same data obtained using the spatially separated pilot injection. As expected, for later injection timings, the $\mathrm{NO}_{x}$ emissions decrease significantly whereas the soot emissions increase. Nevertheless, for the spatially separated injection strategy the soot emissions can be reduced by up to $70 \%$ while maintaining constant $\mathrm{NO}_{x}$ emissions.

The same behaviour can be seen for combustion noise, represented by the maximum pressure rise rate

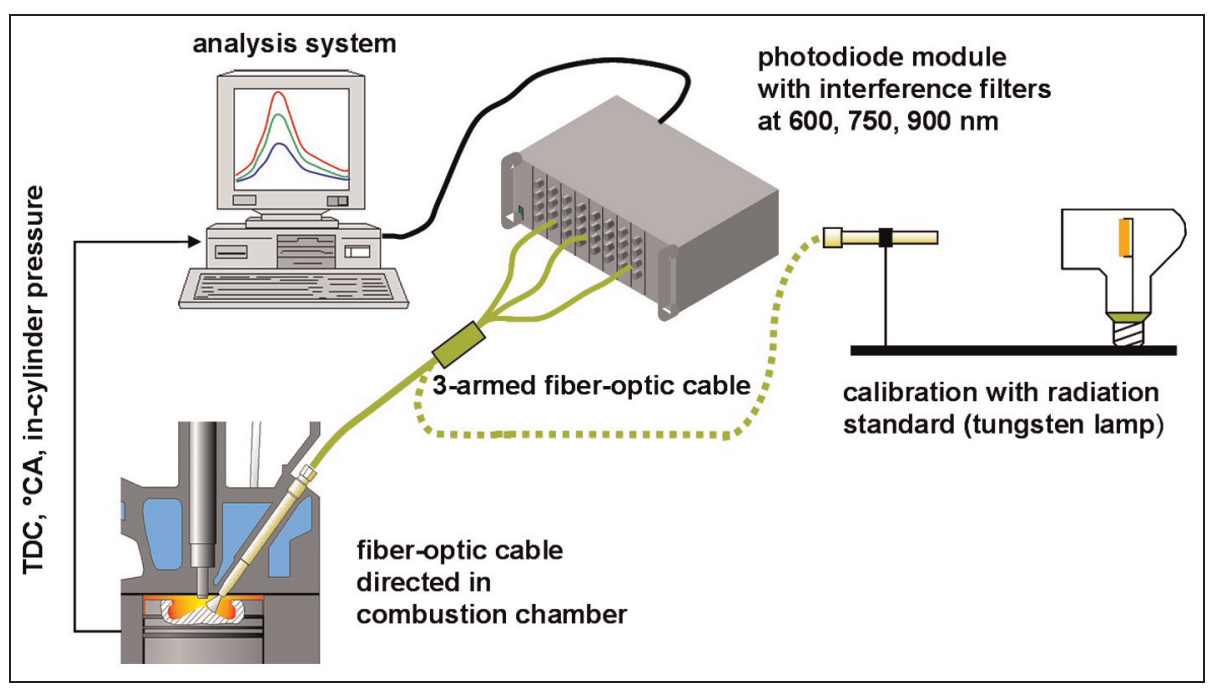

Figure 8. Experimental setup used for the two colour method. 
Table 2. Operating parameters of the engine.

\begin{tabular}{ll}
\hline Property & Value \\
\hline Engine speed & $1175 \mathrm{r} / \mathrm{min}$ \\
Boost pressure & $0.148 \mathrm{MPa}$ \\
Air mass & $94 \mathrm{~kg} / \mathrm{h}$ \\
Equivalence ratio & 0.37 \\
Injection pressure & $180 \mathrm{MPa}$ \\
SOE main injection & $12^{\circ} \mathrm{CA}$ to $6^{\circ} \mathrm{CA} \mathrm{BTDC}$ \\
SOE pilot injection & $12^{\circ} \mathrm{CA}$ before SOE main \\
Mass of fuel in pilot injection & $3 \mathrm{mg} / \mathrm{cycle}$ \\
Mass of fuel in main injection & $66.5 \mathrm{mg} /$ cycle \\
\hline
\end{tabular}

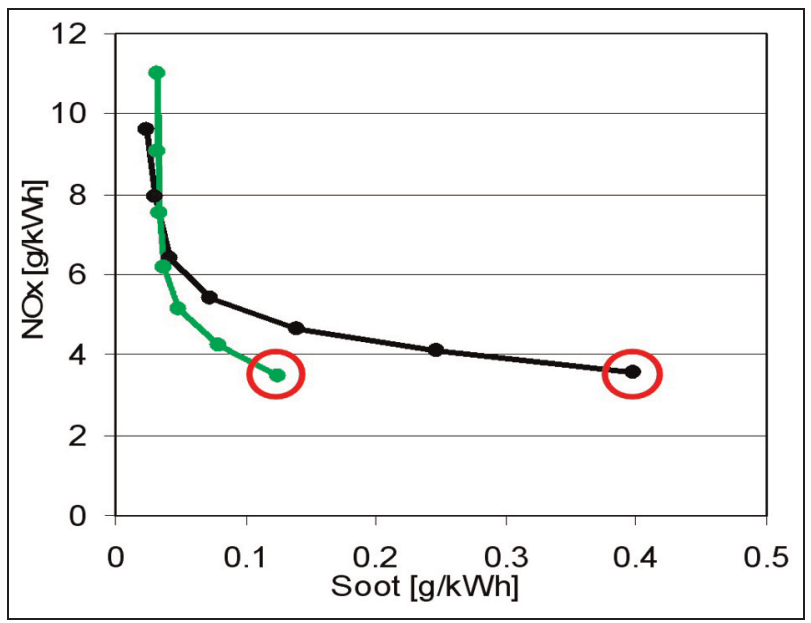

Figure 9. Soot $-\mathrm{NO}_{x}$ trade off for conventional (black) and spatially separated (green/grey) injections.

during combustion as a measure for noise emissions as shown in Figure 10. The combustion noise, which is an important comfort issue, is one of the main reasons for the use of a pilot injection. It can be clearly seen that using retarded injection timing allows the maximum pressure rise rate to be reduced to about $1 \mathrm{MPa} / \mathrm{ms}$ without increasing soot emissions for the spatially separated injection. Compared to this, for a conventional pilot injection strategy the soot emissions are more than four times higher when applying the same pressure rise rate.

The low soot emissions for the spatially separated pilot injection strategy are a result of the improved utilization of the available oxygen in the combustion chamber as well as from the avoidance of direct interaction between the pilot fuel combustion with the liquid main injection fuel. These effects should result in a reduced soot formation during early stages of combustion as well as increased soot oxidation later during combustion.

The new injection strategy not only allows the fuel consumption be kept at the same level as for conventional diesel combustion, but also offers a slightly decreased specific fuel consumption as can be seen in Figure 11. For the absolute values of indicated specific

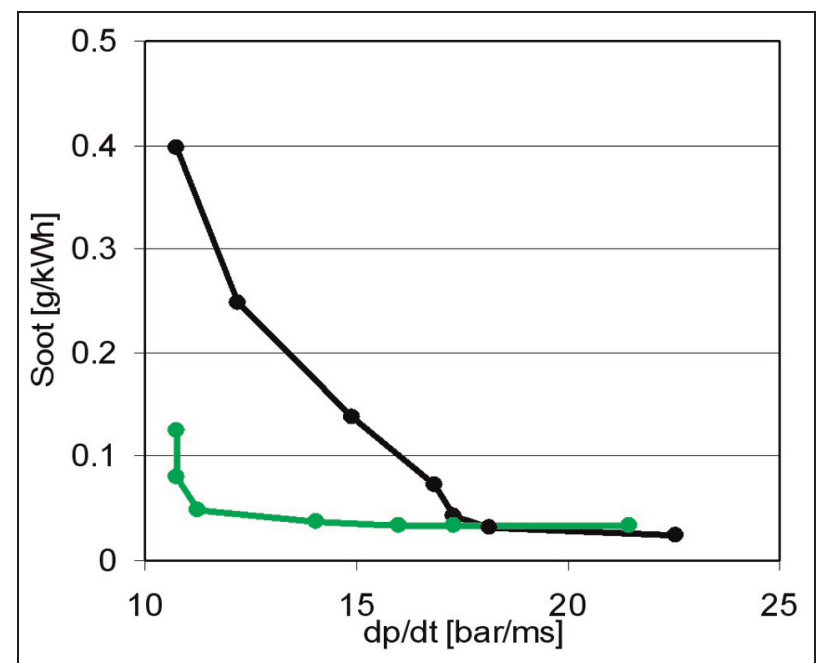

Figure 10. Soot-combustion noise trade off for conventional (black) and spatially separated (green/grey) injections.

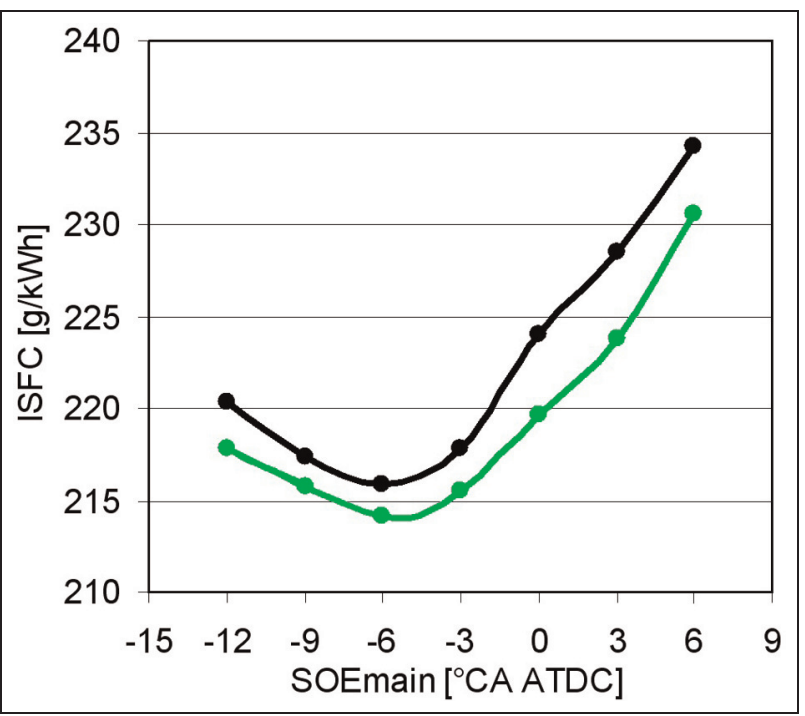

Figure I I. ISFC for conventional (black) and spatially separated (green/grey) injections.

fuel consumption (ISFC), please note that the exhaust back pressure is set to 100 mbar higher than the intake boost pressure to simulate a worst-case turbo charger configuration capable of delivering enough boost pressure. The reduction in fuel consumption is mainly due to significantly decreased $\mathrm{CO}$ emissions for the spatially separate pilot injection compared with that for a conventional pilot injection strategy.

\section{Measurements using the two-colour method}

To confirm the postulated effects on the combustion when separating the pilot fuel from the main fuel the two-colour method was used to determine the differences in the soot formation and oxidation process during combustion both for a conventional pilot and for the spatially separated pilot injection strategies. 


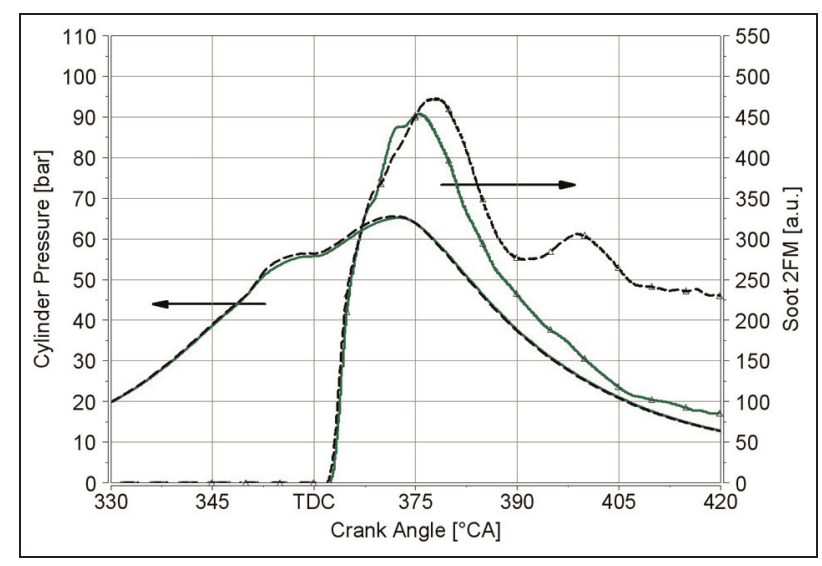

Figure 12. In cylinder soot concentration during combustion for conventional (black dashed) and spatially separated (green) injections.

Figure 12 shows the cylinder pressure and the soot concentration in the combustion chamber for an operating point with significant differences in engine-out soot emissions for conventional and spatially separated pilot injections. The injection timing was $3^{\circ} \mathrm{CA}$ ATDC for the main injection with corresponding values as shown in Table 2. The optical probe for the detection of soot radiation was directed towards the outer areas of the piston bowl so as to be able to observe combustion of main injection as the dominant source for soot formation.

As can be seen, the in-cylinder soot concentration shows almost no differences at the beginning of main combustion both in terms of timing, gradient and maximum value. In contrast, a decrease in soot concentration, and hence the beginning of soot oxidation, starts significantly earlier (about $5^{\circ} \mathrm{CA}$ ) for the spatially separated pilot fuel injection strategy compared with the conventional case. This behaviour indicates that an increased amount of available oxygen to create improved soot oxidation during combustion has a decisive influence on the level of soot emissions. Planned optical investigations on the fuel spray and combustion visualization will provide further information on the in-cylinder processes and therefore the key effects that influence the soot emissions.

\section{Tolerance to changes in the amount of injected pilot fuel}

As already mentioned the soot emission level is very sensitive to changes in the amount of pilot fuel injected. If the amount of pre-injected fuel is only slightly above an optimum level the soot emission level increases disproportionately. By contrast to this, the pilot fuel loses its effect on reducing the premixed part of the combustion if the fuel amount is too small and the combustion takes place as if only a main injection is used. To always inject this correct but small amount of fuel, a complex fuel quantity control procedure has to be performed to ensure a proper pilot injection operation. The extent of the split of the entire injected fuel mass between pilot and main injection was varied to assess the influence of the amount of pilot fuel on the soot emission level. These results were obtained using the early stage split injection design as previously described; however, the basic facts still apply to the latest version of the experimental setup. ${ }^{9}$

The specific soot emission levels for a conventional split injection and the proposed injection strategy as the amount of pilot fuel is varied can be seen in Figure 13. With the conventional injection strategy the soot emission level increases with an increase in the amount of fuel whereas for the spatially separated pilot injection the soot emission level stays at a constant low level. The propagation of the combustion has to be taken into account if a better understanding of the influence of the pilot injection on the soot formation is to be obtained.

Figures 14 and 15 show average cylinder pressure traces after 50 consecutive cycles for the conventional and proposed pilot injections with 4, 6 and $11 \mathrm{mg}$ fuel for the pilot injection, respectively. For the conventional pilot injection a significant difference in the cylinder pressure traces can be seen. For the smallest amount of pilot fuel of $4 \mathrm{mg}$ no effect on the combustion can be observed and the combustion process is similar to a single main injection. With a fuel quantity of $6 \mathrm{mg}$ only a very small effect of pilot combustion on the cylinder pressure can be seen, but this is sufficient to reduce the ignition delay, the premixed combustion part, and hence the maximum pressure rises significantly. For the $11 \mathrm{mg}$ pilot fuel case almost no difference in the main combustion can be seen; however, a further increase in the pilot combustion is evident. The shift in the combustion timing for the main injection and the ignition delay of the main injection changes reduces the ratio of premixed to diffusion-controlled combustion and hence, in combination with the previously described $\lambda$-effect, increases the soot emissions.

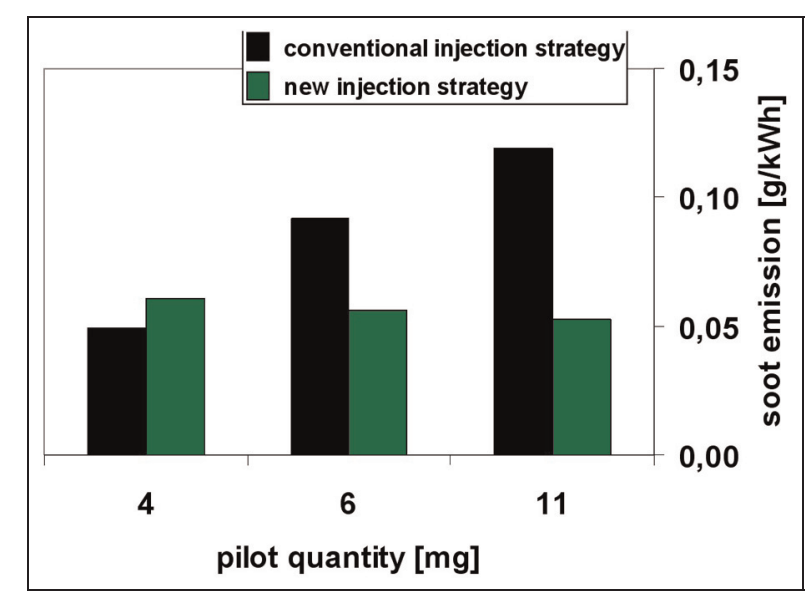

Figure 13. Soot emissions with amount of injected pilot fuel and no EGR. 


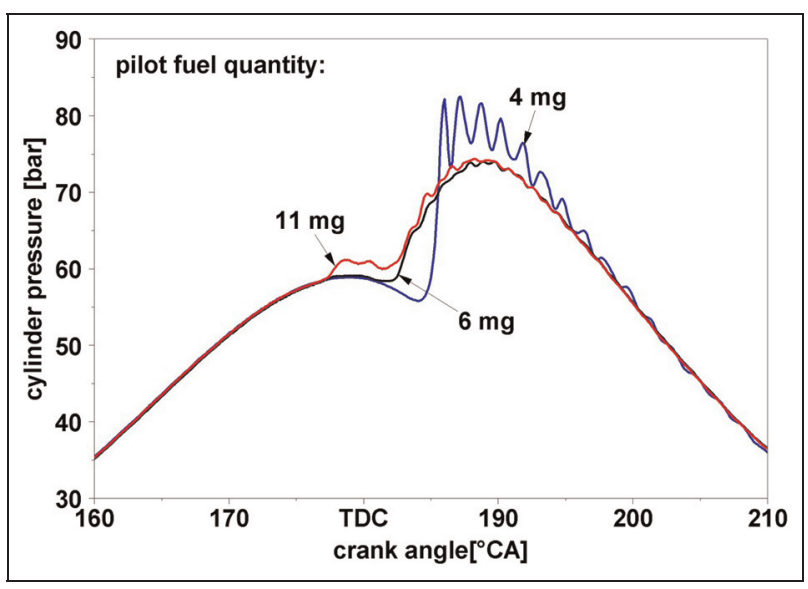

Figure 14. Cylinder pressure obtained using a conventional pilot injection.

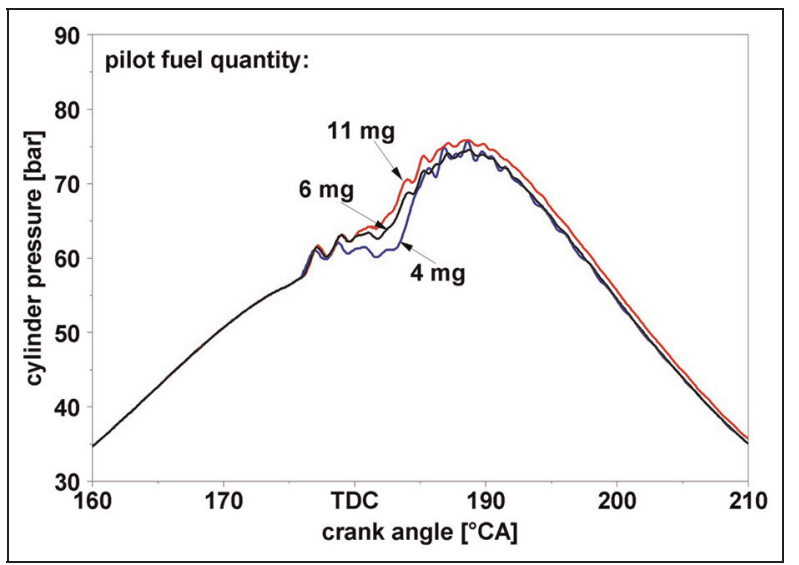

Figure I5. Cylinder pressure obtained using spatially separated pilot and main injections.

The situation observed for the spatially separated pilot and main injections is completely different, refer to Figure 15. As for the conventional injection for the case of $4 \mathrm{mg}$ of fuel in the pilot combustion no effect on the combustion can be observed and the combustion process is similar to a single main injection. Increasing the amount of fuel in the pilot injection results in almost no shift in the combustion timing, only the amount of released heat for the pilot combustion becomes higher. Because of the constant combustion timing and ignition delay for the main injection the ratio of premixed to diffusion-controlled combustion stays constant resulting in almost constant soot emissions.

Additionally, the spatial separation of the fuel injection has two further advantages. First, an increasing amount of pilot fuel does not reduce the initial local air/fuel ratio $\lambda$ for the main injection. In fact with a larger amount of pilot fuel the combustion conditions for the main injection with respect to the available oxygen becomes improved since less of the main fuel is then injected at the same load conditions. Second, as the pilot fuel is not injected through the same nozzle holes as the main injection the nozzle layout can be optimized for the much smaller amount of pilot fuel. For example, only two holes are used for the pilot injection instead of using a standard multi-hole nozzle for the main injector. This also improves the mixture formation for the spatially separated pilot injection compared with the conventional pilot injection.

Summarizing the results obtained after varying the amount of pilot fuel, it can be stated that the spatially separated pilot injection approach has a significantly higher pilot quantity tolerance in terms of soot formation and therefore the complexity associated with the control of small amounts of fuel is reduced.

\section{Conclusions}

Compression ignition engines still offer the highest thermal efficiencies and therefore low specific fuel consumption. Many different technical solutions are available that have demonstrated a good operational performance at the prototype level in their ability to achieve lower pollutant emissions while maintaining good fuel consumption. Conventional heterogeneous diesel combustion still has significant potential to further reduce soot and $\mathrm{NO}_{x}$ emissions using sophisticated technologies such as high-pressure fuel injection, high EGR rates in combination with increased boosting and increased peak firing pressures. This paper presents a spatially separated pilot injection strategy as an alternative to ever increasing injection and boost pressures.

With a spatial separation of the part injection events the major drawback of increased soot emissions created by a conventional pilot injection is overcome while the positive effects on combustion noise due to moderate pressure gradients are maintained. The locally available amount of oxygen is an important parameter that influences the soot formation and oxidation process. By separating the pilot fuel from the main fuel the local air/fuel ratio $\lambda$ for the main injection is increased and soot emissions are significantly reduced in a part load point. With injection timings comparable to conventional pilot injection strategies and moderate injection pressure a soot reduction of about $70 \%$ with constant $\mathrm{NO}_{x}$ emissions is possible.

Summarizing it can be stated, that diesel engines or, more generally speaking, compression ignition engines, have the potential to still be an essential propulsion system in many different fields of application.

\section{Funding}

The authors would like to thank the German Research Foundation for its financial support of this project.

\section{Acknowledgements}

Mr Andreas Binde and Mr Steve Busch are thanked for their support during the experimental tests and subsequent data analysis. 


\section{References}

1. Stiesch G and Merker G. Technische verbrennung motorische verbrennung. Stuttgart, Germany: Teubner Verlag, 1999.

2. Stumpf M. Einfluss motorischer Betriebsparameter auf die Eigenschaften von Russpartikeln und deren messtechnische Erfassung. PhD Thesis, University Karlsruhe, Germany, 2008.

3. Wloka J, Pflaum S and Wachtmeister G. Potential and challenges of a 3000 bar common rail injection system considering engine behavior and emission level. SAE paper $2010011131,2010$.

4. Atzler F, Kastner O, Pfeifer A, et al. Characterisation of mixture formation of a novel directly actuated injector. In: IMechE conference on injection systems for IC engines, London, UK, 1314 May 2009, pp.41 56. UK: Chandos Publishing.

5. Hermann O, Schwab H, Nakagawa M, et al. The break through of common rail systems: closed loop control strategy using an injector with built in pressure sensor. In: IMechE conference on injection systems for IC engines, London, UK, 1314 May 2009, pp.41 56. UK: Chandos Publishing.

6. Gärtner U and Binder K. HCCI im Aufwind haben heterogene Brennverfahren eine Zukunft? In: E Bach (ed.) The fifth Dresdner Motorenkolloquium, Special Issue on: Berichte und Informationen aus Forschung, Lehre und Praxis, HTW Dresden, Dresden, Germany, 2003, pp.45 64 .

7. Curran S, Prikhodko V, Cho K, et al. In cylinder fuel blending of gasoline/diesel for improved efficiency and lowest possible emissions on a multi cylinder light duty diesel engine. SAE paper 201001 2206, 2010.

8. Bach F, Lüft M, Bartosc, S and Spicher U. Influence of diesel ethanol water blended fuels on emissions in diesel engines. MTZ Motortech Zeit 2011; 5: 6268.
9. Wagner U. Experimentelle Untersuchungen ausser und innermotorischer Massnahmen zur Russminimierung bei Dieselmotoren. PhD Thesis, University Karlsruhe, Ger many, 2006.

10. Bockhorn H. Soot formation in combustion: mechanisms and models. Heidelberg, Germany: Springer Verlag, 1994.

11. Badami M, Mallamo F, Millo F and Rossi E. Influence of multiple injection strategies on emissions, combustion noise and BSFC of a DI common rail diesel engine. SAE paper $2002010503,2002$.

12. Kubach H. Lonenstrom als sensorsignal der dieselmotor ischen verbrennung. PhD Thesis, University Karlsruhe, Germany, 2004.

13. Bach E and Velji A. Verbrennungsmotoren Gemischbil dung, Zündung und Verbrennung im Dieselmotor. Lec ture, Univeristy of Applied Science, Dresden, 2002.

14. Houben $M$ and Lepperhoff $G$. Soot formation in local zones of fuel/burned gas mixture in diesel engines. In: The 19th international CIMAC congress on combustion engines, Florence, Italy, 1991.

15. Mayer K. Pyrometrische Untersuchung der Verbrennung in Motoren mit Common Rail Direkteinspritzung mittels einer erweiterten Zwei Farben Methode. PhD Thesis, Uni versity Karlsruhe, Germany, 2000.

16. Hopp M. Untersuchung der Rußoxidation unter dieselmo torischen Randbedingungen. PhD Thesis, RWTH Aachen, Germany, 2001.

17. Müller E, Groenendijk A and Raatz T. Homogene Die selverbrennung Merkmale und Entwicklungsmöglich keiten. In: Dieselmotorentechnik, 2002, vol 630, pp.60 76. Germany: Expert Verlag.

18. Böhm H, Hesse D, Jander H, et al. Measurements about the influence of pressure and temperature in premixed flames. In: The 22nd international symposium on combus tion, 1988, pp.403 411. Germany: Elsevier. 


\section{Repository KITopen}

Dies ist ein Postprint/begutachtetes Manuskript.

Empfohlene Zitierung:

Wagner, U.; Spicher, U.

Advanced heterogeneous diesel combustion with ultra-low engine emissions and low fuel consumption levels.

2013. Proceedings of the Institution of Mechanical Engineers / D, 227.

doi:10.5445/IR/1000098735

Zitierung der Originalveröffentlichung:

Wagner, U.; Spicher, U.

Advanced heterogeneous diesel combustion with ultra-low engine emissions and low fuel consumption levels.

2013. Proceedings of the Institution of Mechanical Engineers / D, 227 (1), 110-119.

doi:10.1177/0954407012441888 